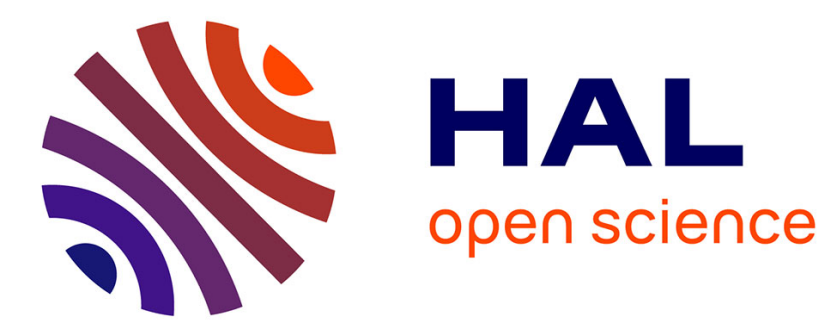

\title{
What is the impact of subject benchmarking?
}

Steve Pidcock

\section{- To cite this version:}

Steve Pidcock. What is the impact of subject benchmarking?. Active Learning in Higher Education, 2006, 7 (2), pp.111-128. 10.1177/1469787406064754 . hal-00571949

\section{HAL Id: hal-00571949 \\ https://hal.science/hal-00571949}

Submitted on 1 Mar 2011

HAL is a multi-disciplinary open access archive for the deposit and dissemination of scientific research documents, whether they are published or not. The documents may come from teaching and research institutions in France or abroad, or from public or private research centers.
L'archive ouverte pluridisciplinaire HAL, est destinée au dépôt et à la diffusion de documents scientifiques de niveau recherche, publiés ou non, émanant des établissements d'enseignement et de recherche français ou étrangers, des laboratoires publics ou privés. 


\author{
STEVE PIDCOCK University of Warwick, UK
}

\begin{abstract}
The introduction of subject benchmarking led to fears of increased external intervention in the activities of universities and a more restrictive view of institutional autonomy, accompanied by an undermining of the academic profession, particularly through the perceived threat of the introduction of a national curriculum for higher education. For this study, semi-structured interviews were conducted in one old and one new university with higher education professionals in chemistry, history and quality assurance, who were asked about their perceptions of subject benchmarking and its impact. The investigation did not bear out the fears articulated at the inception of subject benchmarking. Furthermore, the investigation showed that subject benchmarking was not perceived as having the principal characteristic normally associated with a benchmarking system, in that it was not perceived as leading to improvement. The article ends with suggestions for future research.

KEYWORDS: institutional audit, quality improvement, standards, subject benchmarking
\end{abstract}

\title{
Introduction
}

Subject benchmarking was introduced into UK higher education (HE) in 2000 with the publication of the first Quality Assurance Agency (QAA) subject benchmark statements: these resulted from the report of the National Committee of Inquiry into Higher Education (NCIHE) Higher Education in the Learning Society (NCIHE, 1997), commonly referred to as the Dearing Report. It was the purpose of the NCIHE, chaired by Sir Ron Dearing:

To make recommendations on how the purposes, shape, structure, size and funding of higher education, including support for students, should develop to meet the needs of the United Kingdom over the next 20 years, recognising that higher education embraces teaching, learning, scholarship and research. (NCIHE, 1997: 3)

Dearing himself (NCIHE, 1997: 2) states: 'Much of our report is concerned with material things and with the central role of higher education in the 
economy. It would be surprising were it not so'. Nevertheless, in the committee's (NCIHE, 1997: 72) view, the four main purposes of higher education are: to help individuals to realize their potential; to foster knowledge and understanding; to serve local, regional and national needs; to shape a democratic, civilized, inclusive society. These purposes are enunciated within the context of the committee's (NCIHE, 1997: 3) terms of reference, the third element of which is the principle that 'standards of degrees and other higher education qualifications should be at least maintained, and assured'. In line with this, Dearing (NCIHE, 1997: 163, Recommendation 25) recommends that the QAA should 'work with institutions to establish small, expert teams to provide benchmark information on standards, in particular threshold standards'.

Aldrich (1996: 43) notes considerable concern over assessment in HE: 'The rapid transition from an elite to a mass system has raised fears that standards have been reduced.... In spite of the massive increase in numbers of universities and of university students in the 1990s, firstclass degrees proliferate'. Similarly, Dearing (NCIHE, 1997: 154) records that, with a large increase in student numbers combined with a marked increase in the proportion of First or Upper Second class honours degrees awarded, "many think that it is not plausible to say that standards have not declined'. After proposing a national framework for higher education qualifications (NCIHE, 1997: 143-51 and Recommendation 22: 151), the NCIHE (1997, Recommendation 25: 163) recommends that included in the early work of the QAA should be: "to work with institutions to establish small, expert teams to provide benchmark information on standards, in particular threshold standards, operating within the framework of qualifications, and completing the task by $2000^{\prime}$.

Armstrong (1999: 21) indicates a consequence of the NCIHE's recommendations on quality: 'The assurance that will be sought in the future is that local standards comply with external criteria'. Previously, there had not only been a tacit assumption that everybody knew what a degree from a British university was worth (Brown, 1999: 35), but also, in a small, elite HE system, standards could be implicit (Armstrong, 1999: 11). Any move towards an explicit codification of standards thus represents a significant policy shift in HE. Additionally, in the more recent mass HE, governments are seeking to guarantee value for money and to provide public accountability (Armstrong, 1999: 8).

Whilst such developments may not appear unreasonable, they do nevertheless have their detractors. Cobban (1999: 216), for instance, argues: 'Where such amorphous and elusive subjects as education and scholarship are concerned, the value for money concept is rendered meaningless when 
translated crudely into rigidly defined objectives or targets'. Similarly, the recently imposed exposure to external scrutiny might be seen not only as breaking into the traditional territory of professional groups (Middlehurst, 1992: 24), but also as threatening to undermine the "ideology of professionalism' (Kogan, 1986: 152), explained (Kogan, 1986: 152) as the assumption that, in schools, for instance, 'teachers are doing a good job'. Tapper and Salter (1998: 22) raise further objections, identifying three very significant consequences of the Dearing Report: it represents another move towards the creation of a national curriculum in HE; it offers a more restrictive interpretation of university autonomy; and it represents a threat to the growing diversity of British HE.

In 2002, institutional audit replaced subject review as the QAA's quality assessment mechanism for HE in England (QAA, 2002a: 3), the QAA's (2002b: 3) Handbook for Institutional Audit: England specifying that one of the things on which audit teams will particularly focus is: 'the use made of external reference points, including ... Subject benchmark statements'. Noting that subject review aimed to improve quality (Jowett, 2005: 82), Jowett (2005: 83) argues that, 'by including reference to Subject Benchmark Statements the new [institutional audit] process has included an element of defining frames of reference for a course, but avoided prescription of course outcome'. As expounded by Alstete (1996), benchmarking is used by $\mathrm{HE}$ institutions in order to provide information for quality improvement by searching for best practices. Jackson (1999: xi), however, highlights the attempt to 'reinterpret what has gone before [in HE] in terms of two different notions of benchmarking, namely: developmental benchmarking promoting best practice, and; regulatory benchmarking - assuring quality and standards.' In Jackson's (1999: xi) view: 'Much of the conflict and confusion in discussions about the pros and cons of benchmarking for higher education relates to the inbuilt tension between these two different purposes.'

This article summarizes some of the findings of a small-scale study (Pidcock, 2004) investigating reactions to subject benchmarking during the transitional phase from the initial promulgation of the Dearing-inspired quality agenda for HE into the period introducing the first institutional audits. The study sought to gauge reactions both at the level of individual members of staff within academic disciplines and at institutional level. In particular, the perceived necessity of subject benchmarking was investigated, as was the extent to which benchmarking was seen as leading to improvements in the quality of degrees. Views were also sought on the motivation behind the introduction of subject benchmarking and on the consequences of subject benchmarking both for university professionals and for universities themselves. 


\section{Methodology}

Seeking to understand respondents' perceptions of subject benchmarking and its impact, the study adopts a qualitative methodology: 'One facet of the distinction between quantitative and qualitative research is that the former is orientated to the specific concerns of the investigator and the latter to subjects' perspectives' (Bryman, 1988: 142).

Subject benchmarking was first undertaken in chemistry, history and law (QAA, 1998a: Part IV, 10): the study considers chemistry and history in order to provide exemplars of arts-based and science-based subjects. Reactions to subject benchmarking are investigated in two English universities: one pre-1992 university and one post-1992 university. For each institution, the primary source of data is a series of semi-structured interviews conducted between August 2002 and May 2003 with academic members of staff and with representatives of central quality services. Wragg (2002: 149) notes: 'A semi-structured interview schedule tends to be the one most favoured by educational researchers as it allows respondents to express themselves at length, but offers enough shape to prevent aimless rambling'. In all, 30 academics were interviewed, corresponding to approximately 30 per cent of the full complement, together with four members of institutional quality services. The questions from the interview schedule used with academic staff, and varied only slightly with quality administrators, are shown in Figure 1: some questions included Likert scales ranging from 'very good' to 'very bad' and 'other'.

All but two of the interviews were tape recorded, producing transcripts offered to the respondents for checking, verification and amendment: in the two instances in which permission to record was denied, a written account based on notes was submitted in the same way. Additional data and insights were sought from documentary sources, an approach also affording triangulation of results (Marshall and Rossman, 1999: 194). All data gathering is firmly rooted in informed consent (Fontana and Frey, 1994: 372).

After an initial indexing of the data, analytic categories were developed by studying the texts (Arksey and Knight, 1999: 163). Given the relative brevity of the sections of text resulting from fairly short interviews, the coding was descriptive and interpretative, rather than pattern (Miles and Huberman, 1994: 57). The results of the analysis are presented largely discursively, though additional texture is provided by using simple counting techniques. Based on a small population $(\mathrm{n}=34)$ selected by purposive sampling (Cohen and Manion, 1994: 89), the study makes no claim to generalizability, but does aim to achieve trustworthiness. 
Statement of informed consent

Statement of purpose

Do you mind if I record our conversation?

Would you mind telling me how long you have been teaching in higher education?

Would you mind telling me how long you have been in this department?

1. Could you tell me a little about your experience to date of quality assurance and enhancement?

2. Are you used to working with criteria set by an external agency, such as a professional body?

3. How do you feel about the introduction of benchmarking?

4. How do you react to the (Chemistry) performance criteria and statement of threshold performance (History) statement of the threshold standard established for single honours degrees in Chemistry/History?

5. Would you say that benchmarking has led you to change your approach to your courses?

6. Would you say that benchmarking has had an impact on your professional life?

7. In your view, is benchmarking leading to improvements in quality?

8. Do you think that benchmarking will encourage the dissemination of best practice?

9. In your view, was it necessary to introduce benchmarking?

10. In your view, why was benchmarking introduced?

11. Has benchmarking led to changes in the way you think about your own position as an academic?

12. Has benchmarking led to changes in the way you think about the position of universities in today's society?

13. Is there anything you would like to add concerning benchmarking or threshold standards? [eg. impact of new QAA methodology?]

Many thanks for agreeing to take part in this project.

Would you like to check a transcript of our conversation?

\section{Figure 1 Format of interview schedule used with academic staff}

\section{Findings}

Differences between individual departments and the two universities studied were generally not great, and the small sample size inevitably means that the analysis of discrepancies remains heavily conjectural (Pidcock, 2004: 158). It was remarkable, however, that the strongest expressions of unrest tended to come from the younger members of academic staff, even though, overall, they tended to be positive about the introduction of subject benchmarking and threshold standards. One historian seems to encapsulate the dilemma of the tension between acceptance and independence by commenting on 'the realities of placing lines ... which we have to meet, or boundaries over which we must hurdle . . . they're quite often false', and reflecting: 'as a new member of staff, I'm probably more likely to be 
accepting of these things than the older members of staff; and I am, probably; but....' This raises interesting questions about the persistence of images of academic status and institutional autonomy arising in an elite HE system, but which have perhaps been superseded by the realities of a mass system of HE (cf. Halsey, 1992). In the following presentation, the results of the study are aggregated in the interests of setting out an overall view.

\section{Quality assurance and enhancement}

Generally speaking, the academics interviewed were at least used to the concepts of quality assurance and enhancement, even if their current involvement tended to be limited to student feedback forms and peer observation of teaching. Approximately one quarter of the academics interviewed situated quality assurance and enhancement in an accountability context. Some did this explicitly:

Well, clearly there is in the air, now, the notion of accountability for taxpayers' money, and therefore: there's a lot of money being spent, then one of our key activities will be monitored and vetted. I find it a little hard to disagree with that.

Some respondents indicated an accountability relationship implicitly: 'I think we owe our students a responsibility, which is to ensure that the programmes we deliver are of good quality'.

\section{The introduction of subject benchmarking}

Close knowledge of subject benchmarking was not widespread, with exactly one third of the academics interviewed claiming no familiarity with it. Additionally, there was an almost complete lack in both institutions, at subject, departmental or institutional level, of documentation relating to subject benchmarking.

A little over half of those asked rated the introduction of subject benchmarking as good or very good, with one third remaining neutral: there were no negative ratings. The one respondent replying 'very good' saw the system as a mechanism for facilitating the recognition of degrees: 'so, the benchmarking was basically saying: Right, now, anybody who claims to be a Bachelor in chemistry must understand this'. Ratings of 'good' included reasons such as that any chemist 'needs to know the basics' or that benchmarking 'should ensure that all of the [history] courses are meeting certain standards'. Some appreciated benchmarking 'because it's about trying to define what you think a graduate in the subject is', so that the benchmarking process had given rise to beneficial reflection on the nature of the subject; this view is not shared by all, however: 'it's not exactly helped 
departments to reflect; it's merely provided a template that you follow'. Several respondents expressed unease about a possible 'lack of flexibility' in the benchmarking system: 'My whole fear with anything, when you write down rules, is it can also become restrictive, in their turn'. One respondent took the view that an evaluation of benchmarking "probably depends on how people apply it'. The major concern here was that benchmarking was 'getting close to a national curriculum for higher education', which was interpreted as a bad thing. By contrast, one respondent considered benchmarking to be good as there was a need for consistency across HE in what was being taught, this corresponding to there being 'accepted paradigms within subjects'. Asked about his description of this being 'almost like in a national curriculum', this respondent replied: 'I would say that it's a good thing'.

Slightly under half of those asked rated 'good' the statements of performance criteria and/or threshold standard given in the benchmark document for their subject (nobody rated this 'very good'), and just under a quarter remained neutral; almost one seventh gave negative reactions (though none was classed as 'very bad'). Positive assessments in chemistry included: 'fine' and 'a worthy effort'; and in history: 'a fair enough statement' and 'a useable set of criteria'. Negative assessments, all occurring in chemistry, referred to the vagueness or subjectivity of information listed; alternatively: 'The attainment thing I find confusing. It isn't clear to me whether what it's trying to do is define First Class, IIi, IIii, Third Class degrees'. One respondent observed of threshold standards: 'I think, really, just as an idea it's good', but was 'disappointed' with the resulting documents overall: 'So, I would say bad'.

\section{Subject benchmarking and change}

It is perhaps in the area of benchmarking and change that the most striking findings emerged. Nearly three quarters of the respondents stated that benchmarking had not led academics to change their approach to their courses or institutions to change their approach to quality. A small number felt unable to reply; for the equally small number who answered 'yes', any changes had been mainly presentational. For half of the academics, benchmarking had had no impact on their professional lives: paperwork and administration formed the major reasons for answering 'yes' to this question (just over one third), one individual, for instance, referring to 'this deluge of stuff'. Among the few responses rated 'other', one academic reflected: 'My feeling is that, by creating a kind of, a standard approach, that it can only benefit institutions like ours, which maybe don't have a traditional reputation, being a new university'; this enhanced reputation then 'reflects on me, doesn't it?' 


\section{Subject benchmarking and improvement}

The QAA's (QAA, 2002b: 1) Handbook for Institutional Audit: England states: 'The mission of the Agency is to promote public confidence that the quality of provision and standards of awards in higher education are being safeguarded and enhanced'. For almost half of the respondents, however, benchmarking was not leading to quality improvements; as one academic put it: 'the things that actually get altered are very much exterior gloss rather than genuine content or teaching methods'. Almost as many fell into the category 'other', generally because they did not know. Alongside a small number of somewhat speculative answers, of the kind: 'I would hope that it is', just two respondents identified a contribution to quality improvement. One of these highlighted the transparency of information provided for students and a rethinking of modules, programmes and assessment strategies, whilst nevertheless recognizing a possible alternative view 'that it's a paper exercise, and that you're ticking boxes in order to meet the demands of an outside agency, and then the internal agencies that respond to that. I think people have responded in different ways.' The other positive response combined both of these possibilities:

Indirectly, yes; because I think benchmarking is part of a whole process of what you might call a regulation culture: and whereas that can be rather stifling and bureaucratic and rigid, it does encourage people to reflect on what they do, and I think that sort of reflection is healthy. They will grumble about it and will often fill the forms in just wanting to get it off their back, but I think underneath they do reflect on what they do. And I think that's helpful.

In answer to the question as to whether subject benchmarking would encourage the dissemination of best practice (cf. QAA, 2002b: 12), responses were almost exactly equally distributed across 'yes', 'no' and 'other'. Those answering 'yes' did not do so, generally, with any strong endorsement of this aspect of benchmarking. Those who made explicit what they meant by 'best practice' mostly referred to issues concerned with teaching rather than to considerations of standards, course design or curricular content. Some thought that the dissemination would be achieved by the published benchmarking statements themselves. Negative responses tended to be rather firmer: 'I don't think it was ever intended to do that job'; 'I don't see how, because I think it's so lacking in detail.' For the dissemination of best practice, several respondents in this group referred to the Learning and Teaching Support Network and to conferences. In the category 'other', respondents tended to be unsure of the contribution of benchmarking or very guarded, offering comments such as 'I would hope so'. 


\section{Reasons for the introduction of subject benchmarking}

Only one third of the respondents thought it had been necessary to introduce subject benchmarking. Some of those answering 'yes' referred to the great variety of institutions in HE, and one respondent formulated a different view encountered several times: 'If this process means that there is a minimum standard and that there is a set of aims that we're going about to achieve, then that's no bad thing, as far as I'm concerned.' A telling negative response came from a quality administrator: 'really, the position afterwards doesn't look very different from the position beforehand. It's difficult to imagine why one would have felt it was necessary, given that it doesn't seem to have had much impact.' Respondents ( $n=34$, though 4/34 offered no view) were then asked for their views as to why subject benchmarking had been introduced: the most frequently given explanations are shown in Figure 2. The figures indicate the number of times an item was mentioned.

As in Jowett's (2005) study of Subject Review, political pressure emerged as the predominant perceived reason for the introduction of subject benchmarking, most forcefully in the response: 'Well, I mean, to be brutally honest, Steve: benchmarks are about government watchdogging and not about academic standards. Aren't they? Let's be brutally frank! This is a political game, not an academic game'. Figure 2 shows eight references to standards (direct or indirect), and five to quality, though the distinction between quality and standards was far from clear. Indeed, one quality administrator stated: 'Definitely for the quality agenda. We're looking at standards, here.'

\section{The perceived impact of subject benchmarking on individuals and institutions}

Asked if benchmarking had led to changes in the way they thought about their own position as academics, over two thirds of academics answered 'no', and only one fifth 'yes', generally in terms of diminished autonomy.

Political reasons

Reflects a generalized phenomenon

Considerations of accountability

Demand for quantification and/or measurement

Considerations of standards

Considerations of quality

Reasons relating to trust and/or professionalism

14
11
10
9
8
5
5

Figure 2 Perceived causes of the introduction of subject benchmarking 
No clear pattern emerged among the quality administrators, who were asked about changes in the nature of the academic profession. Asked if benchmarking had led to changes in the way they thought about the position of universities in today's society, two thirds of the respondents answered 'no'. The small number answering 'yes' tended to refer to reduced independence or undermined professionalism: 'makes it more like a school than an institution of higher education'.

At the end of the interview, some respondents did take up the invitation to make additional comments, not infrequently returning, directly or indirectly, to a point made earlier; others raising issues not germane to the study. Respondents were then asked if they thought that the change in QAA methodology would make any difference to the status of subject benchmarking. One third of the respondents provided no data answering this question clearly, and a further third did not know. Two respondents thought that the advent of Institutional Audit would produce no change in the status of subject benchmarking. Five thought that benchmarking would become more important, though one of those five was rather muted: 'It may do. In some ways, one hopes that the benchmarking statements become more central'. In the view of one quality administrator, the new QAA methodology would give benchmarks more significance "because they are coming as a package, now, rather than individually . . . they are being seen as a whole package alongside other quality and standards initiatives. They are being foregrounded more'. A further five respondents thought that benchmarking would become less important. One chemist, for instance, took a view diametrically opposed to that just quoted, since benchmarking was now 'one of a raft of things ... that you're supposed to have taken into account when designing a course.... And therefore their impact as the major influence on curriculum, I think has been diluted, as a consequence of that' (emphasis in original). The strongest reaction to this question came from a quality administrator, who immediately commented on the changes in QAA methodology: 'Well, of course, they greatly reduce [the status of subject benchmarks]'.

\section{Discussion}

The interviews revealed a broad awareness and acceptance of quality assurance principles. Underlying this was often a commitment to public accountability and so an acknowledgement of the need to maintain high standards, though there were frequent instances of academics objecting to the excessive bureaucratic burden of quality assurance (cf. Morley, 2003: 55). However, there was very little to indicate the kind of outlook adopted by Trow (1994: 15): "bureaucratic institutions and their mechanisms are 
the alternative to a relationship of trust between the state and universities'. Nor did the idea of quality assurance seem to undermine perceptions of professionalism, also described by Trow (1994: 27): 'almost everything in a university depends on the inner motivations of teachers'.

Whilst just over half of the respondents gave a positive evaluation of the introduction of benchmarking, almost nobody indicated having changed anything other than presentation as a result of subject benchmarking. One senior chemist, for instance, thought that benchmarking was 'probably good' at the national level, but stated: 'At [name of university], we easily met all the levels, so it is of relatively little value'. This lack of impact suggests the underlying interpretation that benchmarking was viewed as good essentially because of its potential when applied elsewhere. The same senior chemist observed: 'So many places can call themselves universities that it may be of some value to define minimum standards'.

Reactions of this kind need to be assessed in context. Both universities studied are well established and well regarded, and it is possible that attitudes in less mature institutions may differ. At the same time, however, there is evidence that, although HE is changing: 'Things are different but standards are not worse' (Harvey, 2002: 21). Support for this view emerges from the QAA's (QAA, 2003b: 4) own report on Subject Review 1993-2001, which records that, after 2904 Subject Review reports, 'HE provision in England and Northern Ireland was generally found to be of very high quality: the overwhelming majority (99 per cent) of subject review visits resulted in the provision being approved in the first instance'.

The QAA (2003b: 4) overview report further states: 'A new era of quality assurance, including a stronger emphasis on the maintenance and enhancement of academic standards, has already begun'. Part of the associated quality assurance framework is benchmarking, one of a number of tools being adopted from industry and business by higher education (Weeks, 2000: 59). Price (1996: 3) records: 'By common consent [benchmarking] is usually acknowledged as rooted in Japanese manufacturing philosophies of continually seeking inspiration and example from other organizations. Its adoption into western management practice is normally credited to Rank Xerox during the mid 1980s'. Benchmarking as understood by Xerox is: 'A continuous, systematic process of evaluating companies recognized as industry leaders, to determine business and work processes that represent "Best Practices" and establish rational performance goals' (Coopers \& Lybrand and CBI, 1993: 4). For Camp (1989: 12): 'Benchmarking is the search for best practices that lead to superior performance'. Spendolini (1992: 15) emphasizes: 'Perhaps the simplest one-phrase response to the definition question would include some reference to "learning from others"'. In Alstete's (1996: 20) view: 'fundamentally, benchmarking 
involves analyzing performance, practices, and processes, within and between organizations and industries, to obtain information for selfimprovement' (emphases removed). A review of the literature (Pidcock, 2004) shows that benchmarking is normally conceived as being a dynamic process of enhancement and continuous development. Indeed, this widespread view prompted objections to the QAA's benchmarking proposals: 'It was ... pointed out that in normal usage "benchmarking" was a term used to denote a means for continuous improvement of quality and standards; and there was a danger that the proposals ... would lead to stasis' (QAA, 1998b: 18). In its own 'response and proposals' (QAA, 1998b: 19) in answer to such specific issues, this misgiving is not addressed. Significantly, in the study, almost nobody thought that benchmarking was leading to quality improvements and only one third of the respondents saw a link between benchmarking and the dissemination of best practice. On the basis of the fieldwork, therefore, it is not easy to assess the constructive contribution of subject benchmarking to the QAA's 'new era of quality assurance'.

Nevertheless, some respondents took a view similar to that articulated by a senior academic: '[The benchmark statement] would help people who've perhaps not taught a Bachelor's degree before: if they planned to start teaching chemistry Bachelor degrees, they must be careful not to leave out things which are contained within there'. By contrast, this respondent continued: 'But a university that has a reasonable reputation for the subject will, you know, it's almost inconceivable that they're not already doing everything that's in the [benchmark]'. A related reaction is recorded by Hargreaves and Christou (2002: 188): 'To comply with the QAA regulatory framework at Sheffield Hallam University, explicit use of the benchmark statements is expected by course teams in the design and review of courses'. Additionally, discipline audit trails have now been dropped from Institutional Audit (Baty, 2005: 7). Considerations of these kinds invite reflection as to whether the subject benchmark statements, rather than being a separate element of the standards infrastructure (Wright and Williams, 2001: 11), might not be better located as a sub-set of the QAA's (2000) Code of Practice for the Assurance of Academic Quality and Standards in Higher Education. Section 7: Programme Approval, Monitoring and Review.

According to the QAA's (2003a: 10) Institutional Audit: England - Key Features of the First Audits:

In general .... the [audit] reports suggest that the eight institutions have responded appropriately to the introduction of the FEHQ and subject benchmark statements. . . All of the institutions are found to have given consideration to the purpose of these external reference points and undertaken some initial work to address them. 
Unfortunately, there is no explanation or analysis of these comments. In the benchmarking study, neither institution visited was able, at the time of the fieldwork, to provide any substantial documentation relating to subject benchmarking. It did emerge, however, that the new university studied, 'as part of its internal review [of] quality management procedures, became very keen that people took account of benchmarking'. Indeed, a course document within one of its departments had adopted almost verbatim significant sections of the corresponding benchmark statement. One of the departments in the old university, anticipating a QAA visit, 'used the benchmarking as a Bible [respondent laughs]'.

Almost nobody in the study identified subject benchmarking with a national curriculum for $\mathrm{HE}$, though those academics who established the link all did so with strong disapproval: 'That's my only concern about it: that it's the first step on a dreadful route to national curriculum'.

Overall, reactions to subject benchmarking tended to be somewhat subdued. As one academic put it: 'you do find yourself trying to jump through these little hoops that are set, just to get the documentation in order, which, in a way, detracts from the teaching and detracts from other aspects of my job, as well'.

Additional insights into the impact of benchmarking may emerge from the report in the series Outcomes from Institutional Audit announced by the QAA (2005: 3): 'A later paper in the Outcomes ... series will address the use of subject benchmark statements ... in institutions' internal quality and academic standards arrangements'. Similarly, a more manifest contribution to the identification and dissemination of best practice may result from the review of the published benchmark statements programmed to start in April 2005 (QAA, 2004: 12). It is clear, however, that such matters continue to arouse strong feelings, as when Furedi (2005: 54) writes:

In the case of the PGCHE [the element of socialisation involved in all forms of accreditation] is almost exclusively about socialising academics into the ethos of the audit culture that dominates the campus. It is about indoctrinating new lecturers into values of a conformist orientation towards teaching. Academics learn to talk the lingo of best practice, benchmarking and summative assessment.

A challenge confronting QAA benchmarking is the UK's involvement in the Bologna Process (Williams, 2004: 10), especially in view of the 'increasing interest in recent years to apply benchmarking as a tool for quality improvements within higher education in Europe' (Hämäläinen et al., 2003: 5). The QAA's (1999: para. 6.2) own advisory group on multidisciplinary and modular programmes states: 'The Advisory Group ... recommends that the standards of higher education in the UK could be 
better assured through the adoption of an enhancement rather than referent benchmarking process and philosophy' However, Cuthbert (2002: 39) records that this examination of multi-subject courses was abandoned because 'the QAA could not accommodate a fundamental challenge to its subject-based philosophy'. Consequently, not only does the problem of multidisciplinary and modular programmes remain unresolved, but also, at a European Network for Quality Assurance in Higher Education workshop on 'Benchmarking in the Improvement of Higher Education', the QAA presented the task of subject benchmarking groups as, firstly: 'to create reference points, which help define the nature of awards in the subject' (Crozier, in Hämäläinen et al., 2003: 23); and, secondly: 'to formulate or articulate the minimum requirements or expectations of performance for an award in the subject' (Crozier, in Hämäläinen et al., 2003: 24). However, the Burslem Report (HEFCE, 2005: 12), in seeking to improve the Quality Assurance Framework, emphasizes '[t]he wish to develop quality enhancement aspects'. It remains to be seen whether Neave (2005: 19) is correct to describe the Bologna Process as generating a 'field of strife ... in such issues as modes of accreditation, the criteria of quality and its benchmarking'.

In Scotland, of course, the QAA (2003c) has adopted a model of enhancement-led institutional review (ELIR), in which enhancement is defined as 'taking deliberate steps to bring about continuous improvement in the effectiveness of the learning experience of students' (QAA, 2003c: 5 ) and in which subject benchmarking information is listed as one of the common reference points most likely to be included in ELIR (QAA, 2003c: 5). Yet this approach is not without its problems: 'There is a certain amount of evidence that some of those involved in the institutions in this first round of ELIR visits were unsure as to where the emphasis lay or should lie as between assurance and enhancement' (Swinfen, 2004: 9). In the UK, the particular interest HE professionals show in enhancement activity is very clear (Lawton, 2003: 19; 2004: 15). Unfortunately, the nature of improvement in HE remains an unresolved issue (Houston and Studman, 2001: 475). Williams (2002: 1) points out that "neither "assurance" nor "enhancement” carries a simple definition'. Indeed, Morley (2003: 13) suggests that "the concept of improvement in quality assurance can often seem under-theorized in the context of sophisticated analyses in the academy of measurement techniques'. Rather than settling for the comfortable vagueness of continuous improvement simply being 'always trying to do things better' (Williams, 2002: 1), there is a need for a differentiated conceptualization of enhancement if techniques are to be devised for the investigation and evaluation of improvement. Future research could profitably analyse the perceptions and insights of HE professionals in order 
to generate a taxonomy and shared vocabulary of enhancement which could then, in turn, inform the daily activities of those same professionals and foster further discussion and refinement. In a wider context, the development of theoretical models of quality enhancement may prove helpful in 'the bitter but unavowed struggle between individual higher education systems in Western Europe' (Neave, 2005: 19).

Moreover, a rich field for research is the student perspective. Haller (1995: 26) demonstrates that, 'students' evaluated importance of [quality] criteria, as well as their perceptions, changed during the period of the service process'. Material constraints on the benchmarking study discussed here made it impossible to include students: indeed, Hill et al. (2003: 15) indicate that student perceptions of quality generally are under-researched. At the time of the fieldwork described, however, the UK National Union of Students (NUS) did not have a policy on subject benchmarking (NUS: private communication). With the advent of top-up fees and the proposal in the White Paper The Future of Higher Education (DfES, 2003: para. 4.33) to award the university title on the basis of taught degree awarding powers, student perceptions of subject benchmarking become an even more significant area for investigation. Margham and Jackson (1999: 103) argue that quality and standards 'are often used interchangeably to refer to the value and reputation of an institution's programmes of study'. If, however, quality and standards are considered to enjoy a symbiotic relationship (Pidcock, 2004), each having a beneficial impact on the other, then the distillation of student views on the strengths and weaknesses of subject benchmarking could assist all involved to make a valuable contribution to the enrichment and enhancement of the student experience.

\section{Acknowledgements}

I gratefully acknowledge help and advice given in the development of this article by Dr Hugh Busher of the Graduate School of Education at the University of Leicester.

\section{References}

ALDRICH, R. (1996) Education for the Nation. London: Cassell.

Alstete, J. W. (1996) Benchmarking in Higher Education. Adapting Best Practices to Improve.

Washington, DC: The George Washington University Graduate School of Education and Human Development [ASHE-ERIC Higher Education Report No. 5, 1995].

ARKSEY, H. \& KNIGHT, P. (1999) Interviewing for Social Scientists. An Introductory Resource with Examples. London: SAGE.

ARMStrong, M. (1999) 'Historical and Contextual Perspectives on Benchmarking in

Higher Education', in H. Smith, M. Armstrong \& S. Brown (eds) Benchmarking and

Threshold Standards in Higher Education, pp. 7-34. London: Kogan Page.

B ATY, P. (2005) 'Subject Audits Ditched by QAA', Times Higher Education Supplement, 5 August, p. 7.

BRown, s. (1999) 'How Can Threshold Standards Assure and Enhance Quality?', in 
H. Smith, M. Armstrong \& S. Brown (eds) Benchmarking and Threshold Standards in Higher Education, pp. 35-52. London: Kogan Page.

BRYMAN, A. (1988) Quantity and Quality in Social Research. London: Routledge.

CAMP, R. C. (1989) Benchmarking. The Search for Industry Best Practices that Lead to Superior

Performance. Milwaukee, WI: ASQC Quality Press.

Совваn, А. (1999) English University Life in the Middle Ages. London: UCL Press.

COHen, L. \& MANion, L. (1994) Research Methods in Education, 4th edn. London:

Routledge.

COOPERS \& LYBRAND AND CBI (1993) Survey of Benchmarking in the UK. London:

Coopers \& Lybrand and CBI.

CUthbert R. (2002) 'The Impact of National Developments on Institutional

Practice', in S. Ketteridge, S. Marshall \& H. Fry (eds) The Effective Academic. A Handbook

for Enhanced Academic Practice, pp. 32-48. London: Kogan Page.

DFEs (Department for Education and Skills) (2003) The Future of Higher Education.

Norwich: The Stationery Office.

FOnTANA, A. \& FREY, J. H. (1994) 'Interviewing: The Art of Science', in

N. K. Denzin \& Y. S. Lincoln (eds) Handbook of Qualitative Research, pp. 361-76.

Thousand Oaks: SAGE.

FUREDi, F. (2005) ‘For Accreditation, See Indoctrination', Times Higher Education

Supplement, 6 May, p. 54.

Halsey, A. H. (1992) Decline of Donnish Dominion. The British Academic Professions in the

Twentieth Century, revised and expanded. Oxford: Clarendon Press.

HÄMÄLÄINEN, K., HÄMÄLÄINEN, K., JESSEN, A. D., KAARTINEN-KOUTANIEMi, M.

\& KRISTOFFERSEN, D. (2003) Benchmarking in the Improvement of Higher Education.

Helsinki: European Network for Quality Assurance in Higher Education [ENQA

Workshop Reports 2].

hargreaves, J. \& Christou, A. (2002) 'An Institutional Perspective on QAA

Subject Benchmarking', Quality Assurance in Education 10(3): 187-91.

HARVEY, L. (2002) 'The End of Quality?', Quality in Higher Education 8(1): 5-22.

HEFCE (2005) Review of the Quality Assurance Framework. Phase One Outcomes. Bristol: HEFCE

[July 2005/35].

Hill, Y., LOMAS, L. \& MACGRegor, J. (2003) 'Students' Perceptions of Quality in

Higher Education', Quality Assurance in Education 11(1): 15-20.

HOUSTON, D. \& STUDMAN, C. J. (2001) 'Quality Management and the University: A

Deafening Clash of Metaphors?', Assessment \& Evaluation in Higher Education 26(5): 475-87.

JACKSON, N. (1999) 'Foreword', in H. Smith, M. Armstrong \& S. Brown (eds)

Benchmarking and Threshold Standards in Higher Education, pp. xi-xiii. London: Kogan Page. jowett, A. K. (2005) 'Did the Market Force Subject Review?', Active Learning in Higher

Education 6(1): 73-86.

KOGAN, M. (1986) Education Accountability: An Analytic Overview. London: Hutchinson.

LAWton, J. (2003) 'Results of Reader Survey', Higher Quality 13: 18-19.

LAWTON, J. (2004) 'Feedback from our Subscribers' Meeting', Higher Quality 15: 15.

MARGHAM, J. P. \& JACKSON, S. (1999) 'Benchmarking Across Subjects in an

Institution', in H. Smith, M. Armstrong \& S. Brown (eds) Benchmarking and Threshold

Standards in Higher Education, pp. 103-15. London: Kogan Page.

MARShall, C. \& ROSSMAn, G. B. (1999) Designing Qualitative Research, 3rd edn.

Thousand Oaks, CA: SAGE.

Middlehurst, R. (1992) 'Quality: An Organising Principle for Higher Education?',

Higher Education Quarterly 46(1): 20-38. 
miles, M. B. \& huberman, A. M. (1994) Qualitative Data Analysis, 2nd edn. Thousand Oaks, CA: SAGE.

MORLEY, L. (2003) Quality and Power in Higher Education. Maidenhead: Society for

Research into Higher Education \& Open University Press.

NCIHE (1997) Higher Education in the Learning Society. London: HMSO.

NeAve, G. (2005) 'The Supermarketed University: Reform, Vision and Ambiguity in British Higher Education', Perspectives 9(1): 17-22.

PIDCOCK, s. (2004) Conformity or Improvement? Subject Benchmarking in Some Subject Areas in Some Universities, unpublished EdD thesis, Graduate School of Education: University of Leicester.

PRICE, I. (1996) A Plain Person's Guide to Benchmarking. Sheffield: Sheffield Hallam University, Unit for Facilities Management Research.

QAA (1998a) 'Consultation: Developing the Quality Assurance and Standards

Framework for UK Higher Education', Higher Quality 3: 3-23.

QAA (1998b) 'Responses to an Agenda for Quality', Higher Quality 4: 13-21.

QAA (1999) Benchmarking Academic Standards. The Advisory Group on Multi-disciplinary and

Modular Programmes. Final Report. Gloucester: QAA.

QAA (2000) Code of Practice for the Assurance of Academic Quality and Standards in Higher Education.

Section 7: Programme Approval, Monitoring and Review. Gloucester: QAA [IRD 630 5/2000].

QAA (2002a) QAA External Review Process for Higher Education in England: Operational Description.

Gloucester: QAA [QAA 019 03/02].

QAA (2002b) Handbook for Institutional Audit: England. Gloucester: QAA [QAA 021 7/2002].

QAA (2003a) Institutional Audit: England - Key Features of the First Audits. Gloucester: QAA.

QAA (2003b) Learning from Subject Review 1993-2001. Sharing Good Practice. Gloucester:

QAA [QAA 040 12/03].

QAA (2003c) Handbook for Enhancement-led Institutional Review: Scotland. Gloucester: QAA

[QAA 033 04/2003].

QAA (2004) Recognition Scheme for Subject Benchmark Statements. Gloucester: QAA [QAA 066

$10 / 2004]$.

QAA (2005) Outcomes from Institutional Audit. Programme Specifications. Gloucester: QAA

[QAA 077 04/05].

SPend olini, M. J. (1992) The Benchmarking Book. New York: American Management

Association.

SWINFEN, D. (2004) Enhancement-led Institutional Review 2003-04. Independent Observer report.

Gloucester: QAA: http:// www.qaa.ac.uk [accessed 9 May 2005].

TAPPER, E. R. \& SAlteR, B. G. (1998) 'The Dearing Report and the Maintenance of

Academic Standards: Towards a New Academic Corporatism’, Higher Education

Quarterly 52(1): 22-34.

TROW, M. (1994) Managerialism and the Academic Profession: Quality and Control. Quality

Support Centre: Higher Education Report No 2. London: The Open University.

WeEKS, P. (2000) 'Benchmarking in Higher Education: An Australian Case Study',

Innovations in Education and Training International 37(1): 59-67.

Williams, P. (2002) 'Anyone for Enhancement?', Higher Quality 11: 1-2.

Williams, P. (2004) 'International Developments', Higher Quality 14: 10.

WRAG G, T. (2002) 'Interviewing', in M. Coleman \& A. R. Briggs (eds) Research Methods in Educational Leadership and Management, pp. 143-58. London: Paul Chapman.

WRight, P. \& Williams, P. (2001) 'How it all Fits Together: Quality Assurance and the Standards Infrastructure', Higher Quality 9: 11-12. 
ACtive LEARNING IN HIGHER EDUCATION 7 (2)

\section{Biographical note}

STEVe PIDCOCK is Associate Director of the Language Centre at the University of Warwick.

Address: Language Centre, University of Warwick, Coventry CV4 7AL, UK.

[email: Steve.Pidcock@warwick.ac.uk] 